\title{
COLABORACIÓN ESPECIAL
}

\section{ÉTICA PROFESIONAL Y ÉTICA INSTITUCIONAL: ¿CONVERGENCIA O CONFLICTO?}

\section{Diego Gracia}

Unidad de Historia de la Medicina. Facultad de Medicina. Universidad Complutense de Madrid.

\section{RESUMEN}

Durante las últimas décadas ha tenido lugar un amplio debate sobre las profesiones en general, y sobre la profesión médica en particular. La idea clásica de que los profesionales se rigen por una «moralidad especial» distinta de la moralidad común, que entre otras cosas les dota de impunidad jurídica, ha entrado en crisis. Esto ha producido un gran desconcierto en los cuerpos profesionales, que no han sabido bien cómo redefinir su identidad. Algunos conceptos, como el de «fines internos» de la actividad profesional, no han hecho más que complicar la situación. Por otra parte, la presencia cada vez más activa de las fuerzas del mercado en la economía sanitaria, ha hecho que los profesionales de la medicina vieran ciertas decisiones de los gestores sanitarios como incompatibles con la moralidad de su profesión. Esto ha dado lugar a un debate que en el ámbito anglosajón, se conoce con el nombre de New Professionalism. En él se están ventilando cuestiones fundamentales sobre la identidad de los profesionales sanitarios de cara al siglo XXI.

Palabras clave: Actitud del personal de salud. Bioética. Economía sanitaria. Gestión sanitaria. Personal de salud.

\section{ABSTRACT
Professional ethic and institutional ethic: convergency or conflict

During the last decades, an important debate about professions in general, and particularly about the medical profession, has taken place. The classic idea that professionals do have a «special morality», different from the common morality, which among other things give them legal impunity, came to a head. This cause a great deal of confusion among the professionals, incapable of reacting and redefining precisely their own identity. Some new concepts, like that of «internal morality» of professional activities, made the debate more difficult and confusing. On the other hand, the everyday more powerful influence of free market forces in the health care economy, has made that some decisions taken by health care managers would be considered by physicians as opposed to their professional duties and incompatible with them. This has been the origin of a debate about what is called in North America «New Professionalism». This debate deals with basic questions about the health care professional's identity at the beginning of this new Century.

Key words: Ethics.Health economics. Health personnel. Attitude of health personnel. Management.

\section{INTRODUCCIÓN}

En todo el mundo occidental se han producido cambios muy profundos durante las últimas décadas en dos campos fundamenta-

Correspondencia:

Diego Gracia

Unidad de Historia de la Medicina

Departamento de Medicina Preventiva, Salud Pública e Historia de la Ciencia

Facultad de Medicina

Universidad Complutense de Madrid

28040 Madrid

Correo electrónico:dmgg@med.ucm.es les de la actividad sanitaria: el profesional y el institucional. Ya no es posible seguir manteniendo las tesis que han conservado vigencia a lo largo de más de dos mil años sobre la ética profesional en general, y la ética de las profesiones sanitarias, en particular. Por otra parte, la actividad sanitaria ha sufrido un progresivo proceso de institucionalización, como consecuencia de su creciente complejidad técnica y el incremento exponencial de los costes económicos. Esto ha hecho que hayan surgido nuevas ideas y propuestas, tanto en el campo de la ética profesional, 
como en el de la ética institucional. En las últimas décadas, algunas de estas propuestas han provocado importantes conflictos. Muchos de estos conflictos han intentado resolverse por vías improcedentes, consistentes unas veces en el triunfo de las tesis de los economistas y gestores sobre los médicos, y otras en lo contrario. El tiempo ha demostrado que ninguna de esas actitudes es correcta, y que esas dos éticas están llamadas a entenderse. De la confrontación hay que pasar a la colaboración; del conflicto a la convergencia. Para lo cual ambas han de tener muy claramente definidos sus propios códigos de conducta. En el caso de la profesión médica, eso es lo que ha dado lugar al movimiento conocido con el nombre de $\mathrm{New}$ Professionalism. En él se están ventilando cuestiones fundamentales sobre la identidad de las profesiones sanitarias de cara al siglo XXI.

\section{LAS PROFESIONES Y LA ÉTICA}

Desde hace años se libra una dura batalla en el campo de la ética de las profesiones. Los cambios ocurridos en el mundo de la medicina son de tal calibre, que los mismos fundamentos de la profesión han entrado en debate. El punto de partida, o mejor el telón de fondo, lo constituye la imagen tradicional o clásica de las profesiones. Para saber lo que esto significa, nada mejor que acudir a la clásica descripción de Parsons ${ }^{1}$. Los profesionales han sido vistos durante siglos, o mejor milenios, como seres investidos de un rol superior que les concedía un estatus de excepción. Esto tenía sus consecuencias morales, dado que les situaba, para utilizar la conocida frase de Nietzsche, «más allá del bien y del mal».

Esto ha cambiado muy drásticamente en las últimas décadas, como han dejado en claro los estudios sociológicos aparecidos durante los años sesenta y setenta, entre otros los de Eliot Friedson ${ }^{2}$. Es en esas décadas cuando los roles de excepción comenza- ron poco a poco a sufrir una crítica implacable. Las diferencias clásicas entre oficios y profesiones comienzan a reducirse, hasta el punto de que hoy ya no es posible seguir hablando de una «moralidad especial» de las profesiones a diferencia de los oficios. Hay, sí, peculiaridades relacionadas con el tipo de actividad que se realiza. Pero esto no afecta sólo a las profesiones clásicas sino a todos y cada uno de los roles ocupacionales. El médico tiene unas obligaciones específicas relacionadas con su actividad, pero lo mismo les sucede a otras muchas actividades que nunca fueron consideradas profesiones, como pueden ser los bomberos o los pilotos de aeronaves.

Esta pérdida de las señas de identidad tradicionales ha hecho que las profesiones clásicas hayan entrado en una auténtica crisis de identidad. ¿Qué es un médico? ¿Qué es un profesional? ¿Es posible decir algo sensato en este tema sin caer en los tópicos tradicionales? Al plantearse estas cuestiones, el testigo ha pasado de las manos de los sociólogos a las de los filósofos y, en el caso de la medicina, a las de los bioeticistas.

Las primeras respuestas datan de finales de los años setenta. Uno de los primeros en saltar a la palestra fue Robert M. Veatch, que en 1979 publicó un importante artículo en el que se enfrentaba con las dos tesis de mayor vigencia: la tradicional, ya descrita, y la defendida por todos los partidarios del libre mercado, en especial los economistas, para los que las profesiones funcionan como verdaderos monopolios, lo que necesariamente lleva a una disminución de las calidad de los servicios y un aumento del precio. La cuestión está, pues, en elegir entre el monopolio y el puro mercado ${ }^{3}$. Veatch no considera aceptable ninguna de esas posturas. La primera, porque se suele defender apelando a la necesidad de que los profesionales actúen conforme a una professional ethics distinta y más exigente que la llamada common morality. Según este esquema, los profesionales tendrían obligaciones específicas, muy 
superiores a las de los demás mortales, que exigirían el que cada profesión funcionara como grupo cerrado con normas internas que se establecen desde el interior del propio grupo. Eso sería la ética profesional, distinta y distante de los preceptos propios de la llamada moralidad común. Ni que decir tiene que esta es la expresión de lo que clásicamente han sido las profesiones en la cultura occidental.

En el polo opuesto está el otro modelo, aquel que quiere hacer de las actividades profesionales ocupaciones como cualesquiera otras, regidas por las leyes del libre mercado. Veatch pone como ejemplo para el contraste de esta teoría el tema de los anuncios de los médicos a fin de atraer clientela. No hay duda que los anuncios publicitarios son parte de las tácticas consideradas normales en el mundo del libre comercio. En medicina, sin embargo, siempre se ha considerado improcedente. El primer código moderno de ética médica, el aprobado por la AMA en 1847, prohibe a los médicos «public advertisements». Y tras él podrían citarse una larga serie de códigos y normas ulteriores. De hecho, los comités de nuestros Colegios de médicos se denominan «Comités de Deontología, Derecho médico y Visado». El visado es el modo de controlar por parte del Colegio los rótulos, carteles o anuncios de los profesionales.

Tras discutir los pros y contras de estas dos posturas, Veatch opta por una tercera. Su tesis es que la moralidad propia de las profesiones no es distinta de la moralidad común, y que por tanto no puede hablarse de algo así como de una moralidad especial, pero que tampoco se trata de una actividad estrictamente comercial a la que puedan aplicarse las reglas del libre mercado. Buscando una salida intermedia entre esos dos extremos, llega a la conclusión de que la ética profesional es «role specific». Todas las ocupaciones son roles sociales, y todas van acompañadas de unas obligaciones específicas. Esto no es privativo de las profesiones. También se da en los llamados clásicamente oficios. El bombero tiene unas obligaciones morales derivadas de su actividad, y el piloto de avión, también. El médico, debido a su rol, tiene unas muy específicas. Veatch cree que ellas son el resultado de un contrato, tácito o explícito, que la profesión establece con la sociedad, y en la que cada parte asume obligaciones específicas.

Es probable que el lector haya quedado bastante satisfecho con la solución propuesta por Veatch. Pero de hecho ha sido una fuente de problemas. Porque la teoría del contrato tiene una larga y ciertamente no pacífica historia. Como es bien sabido, los politólogos del Renacimiento y posteriores han solido fundamentar el Estado en un contrato social efectuado entre los miembros de una comunidad humana. El Estado civil sería consecuencia de ese acuerdo de voluntades. La agrupación anterior no podría ser llamada civil sino sólo natural.

Pero esto, argumentan los más clásicos, no deja de ser extraño. Se dice que el contrato lo hacen los miembros de una comunidad humana. Pero si se trata de una comunidad, tiene ya una cierta estructura, no sólo biológica sino también social y política. Lo cual supone tanto como afirmar que hay un Estado civil anterior al Estado que fundamenta el llamado contrato social. O dicho en otros términos, el Estado es una comunidad natural antes que un contrato social. Ésta fue, de hecho, la opinión clásica, como lo demuestra la República de Platón y la Política de Aristóteles. Esta última comienza con las siguientes palabras: «Toda Estado (pólis) es una comunidad (koinonía), y toda comunidad está constituida en vista de algún bien» ${ }^{4}$.

El recurso a Platón y Aristóteles es interesante, pues permite explicar muchas cosas. La tesis de ambos es que todas las cosas de la naturaleza, incluidas las estructuras sociales, tienen un fin interno. Esto es lo que los clásicos llamaron su télos o fin natural. Toda estructura tiene como finalidad el cumplir una función, que constituye por eso mismo 
la razón de ser o la esencia de esa estructura. El télos nos da siempre la razón de ser de las estructuras de la naturaleza y, por tanto, su bien. Lo dice expresamente Aristóteles en las primeras líneas de la Ética a Nicómaco: «Todo arte y toda investigación, y del mismo modo toda acción y elección, parecen tender a algún bien; por esto se ha dicho con razón que el bien es aquello a que todas las cosas tienden» 5 .

Si esto es así, entonces resulta claro que para definir una profesión es necesario identificar su télos o finalidad interna, es decir, aquella función a la que naturalmente se dirige. En el caso de la medicina parece claro que ese fin es la promoción de la salud y de la vida. Hay muchos textos de Aristóteles en este sentido. Platón, por su parte, dice: «Por causa de la enfermedad, que es un mal, es amigo [el enfermo] de la medicina, y la medicina es un bien. Y es por la salud por lo que la medicina ha adquirido esta amistad [del enfermo], pues la medicina es un bien» ${ }^{6}$.

Esta idea se halla en la base de la teoría clásica de las profesiones, pero remozada ha entrado también en la polémica posterior a los años sesenta. De hecho, en el caso concreto de la profesión médica, la defendió Leo Kass en $1975^{7}$, y Edmund Pellegrino a partir del año $1976^{8}$. La tesis de éste es que la medicina parte del «hecho de la enfermedad» y del «acto de la profesión». Este acto no puede consistir en otra cosa que en la curación de la enfermedad de los pacientes, de tal modo que todo acto que no vaya dirigido a promover y prolongar la vida y la salud de las personas, va en contra de los fines internos de la profesión médica.

Esta tesis se vio muy reforzada el año 1981, cuando un filósofo norteamericano de ascendencia escolástica, Alasdair MacIntyre, publicó su célebre libro After virtue ${ }^{9}$. En él defiende la tesis de que las prácticas sociales, como son las profesiones, tienen siempre por objeto la consecución de lo que llama internal goods, bienes internos. Para definir los deberes de una profesión lo primero que es necesario es conocer cuáles son sus bienes internos. Ni que decir tiene que los de la medicina son los antes citados, la promoción de la vida y la salud.

Era necesario establecer este marco para introducir ahora en él un término que ha hecho especial fortuna, el de internal morality o moralidad interna de las profesiones. El primero que lo utilizó fue Lon L. Fuller en 1963 y más ampliamente en 1969, en el campo de la filosofía jurídica y, más concretamente, en los debates sobre la ley natural ${ }^{10}$. Fuller, lo mismo que Finnis, se aparta de la tesis crasamente naturalista de los pensadores antiguos. No es que todas las cosas de la naturaleza, incluidas las estructuras sociales, tengan un fin interno. Por Fuller, como por Finnis ${ }^{11}$, ha pasado distinción moderna entre orden natural y orden moral o humano. No es que las cosas de la naturaleza tengan una teleología interna, es que las actividades humanas la tienen. El ser humano se propone fines, y en eso consiste su moralidad, en justificar ante sí mismo y ante los demás esos fines que se propone. Esa justificación no es meramente externa, la aprobación o reprobación por parte de otras personas. Hay una sanción interna. Y ésta viene dada por la convergencia del objetivo de la acción con la finalidad interna de la actividad. Por ejemplo, la salud es un bien intrínseco, y su logro constituye la finalidad interna de la medicina. La medicina se justifica moral y legalmente en razón de ese bien intrínseco, y por tanto toda acción que vaya en contra de él ha de considerarse como moralmente injustificable.

Fuller desarrolló la idea de «moralidad interna» a propósito de los debates sobre la ley natural y la moralidad de la ley. Pero su punto de vista fue aplicado por John Ladd al caso concreto de la medicina en $1983^{12}$. A partir de ese momento fue creciendo la temperatura en el mundillo de la bioética sobre el modo de definir la «moralidad común con especificidad de rol» que vimos defender a Veatch. La cuestión está en saber si las obli- 
gaciones inherentes al rol médico vienen determinadas interna o externamente; por tanto, si se hallan definidas desde dentro de la propia actividad o son el resultado de un acuerdo social. La expresión más acabada de esta polémica se encuentra en el número 6 del año 2001, de la revista The Journal of Medicine and Philosophy.

¿Cabe dirimir esta polémica? Personalmente creo que sí. Y ello porque en todo el tema de la moralidad interna de las profesiones late una perenne confusión entre valores y prácticas. No me cabe la menor duda de que la salud es un valor, como lo es también la vida, y que además una y otra son valores que con Moore podemos llamar «intrínsecos». De hecho, si por un experimento mental pensamos en un mundo sin salud o sin vida, veríamos que se habría perdido algo importante. Lo cual significa que ambos son valores intrínsecos. De esto no hay duda. Lo que ya no resulta tan claro es que a partir de ahí pueda concluirse, como hacen los partidarios de la moralidad interna, que esos valores son los definitorios de la actividad médica. No es bueno confundir valores con prácticas. Veamos por qué.

Cualquier práctica humana consiste siempre en la realización de valores. Pero una práctica no tiene por qué identificarse necesariamente, y menos de modo exclusivo, en la realización de un valor determinado. $\mathrm{La}$ razón de esto es obvia: en toda práctica intervienen siempre varios valores, que además entran en conflicto entre sí. Qué valor deberá realizarse en cada caso, es cosa que no puede establecerse a priori, sin tener en cuenta la ponderación de las circunstancias y la evaluación de las consecuencias previsibles. Toda profesión es una práctica, y como tal en ella se dan continuamente conflictos de valores. Cómo deben resolverse esos conflictos, es cosa que habrá de determinarse en cada caso, analizando lo que en él «debe»o «no debe» hacerse.

Y aquí llegamos al punto fundamental. La ética tiene por objeto determinar lo que debe o no debe hacerse. De ahí que sea siempre práctica. La ética tiene que ver con la praxis. En eso se diferencia de la axiología, la ciencia de los valores. Los juicios morales son imperativos, cosa que no les sucede a los juicios de valor. La medicina, en tanto que profesión, tiene una ética, y esa ética se ocupa de lo que el profesional debe o no debe hacer. La ética consiste siempre en la realización de valores, y por tanto la ética profesional se ocupa de ellos. Pero lo que define la profesión no es un valor o varios valores en sí, sino una práctica, o si se prefiere, una ética. Hay valores que en caso de conflicto con otros tienen que ceder o, lo que es lo mismo, no pueden realizarse. Esos valores no definen en esos casos lo que se debe hacer, ni por tanto la ética. Confundir los valores más importantes de la profesión médica, como son la vida y la salud, con los únicos que el médico ha de tener en cuenta y por tanto con los que tienen que triunfar sobre todos los demás a cualquier precio, es volver a las andadas, seguir defendiendo bajo rostro nuevo las ideas de siempre, que eran, precisamente, aquellas que se trataba de superar.

Pero si la medicina es una profesión que no se define tanto por valores como por prácticas o por criterios éticos, la cuestión está ahora en determinar, si es posible, cuáles son esos criterios. Dicho de otra manera, de lo que se trata es de saber en qué consiste o cómo se define un buen profesional de la medicina. Es lo que hoy se conoce con el nombre de new professionalism en medicina, nuevo profesionalismo o nueva profesionalidad, entendiendo por tal las condiciones y características del buen ejercicio profesional. De ahí que nuestro tema haya de ser ahora el de buscar el contenido de la nueva profesionalidad en medicina.

\section{ACTUALIDAD DE UNA POLÉMICA}

En noviembre del año 1999, apareció publicado en el $N$ Engl J Med un artículo firmado por Wynia MK, Latham SR, Kao AC, 
Berg JW y Emanuel LL, titulado Medical professionalism in society ${ }^{13}$. Sus primeras líneas decían lo siguiente: «Hoy, a las puertas de una nueva centuria, la genuina profesionalidad médica está en peligro. Se ha producido una creciente perversión de la relación clínica por los incentivos financieros, la fiera competencia del mercado y la erosión de la confianza del paciente, y el médico se halla poco y mal equipado para enfrentarse a esta situación. Sobre el papel de la profesionalidad se ha hablado tan poco que prácticamdente ha desaparecido en la batalla entre quienes están a favor de la competencia del mercado en una industria de un trillón de dólares [americanos] y aquellos que buscan una mayor regulación gubernamental. Y los médicos se han sentido presos entre estos dos campos.»

En el mes de febrero del año 2002 publicaron simultáneamente las revistas Lancet, en Europa, y Annals of Internal Medicine, en los Estados Unidos, un documento titulado Medical Professionalism in the new millenium: A Physicians' Charter ${ }^{14}$. El término ha pasado al lenguaje usual en la expresión «vuelos charter», contexto en el que tiene el sentido de «alquiler» de un avión o un vuelo. Este uso, en cualquier caso, nos acerca más al sentido más propio del término, que es el de «contrato» escrito o «regulación». El artículo apareció publicado en castellano en Medicina clínica en mayo de ese mismo año, y en él se traducía charter por «regulación», lo cual no es incorrecto, pero tampoco expresa el sentido más profundo del término en inglés ${ }^{15}$. Tan no lo expresa, que al traducir el título al inglés (lo cual no deja de ser curioso, porque siendo el artículo una traducción del inglés, los traductores de los títulos de Medicina clínica al inglés no se dieron cuenta de este hecho y elaboraron su propia traducción, en la que, curiosamente, el término charter desaparece, sin duda porque la palabra española «regulación» no lo traduce bien) cambiaron el título, que quedó de la siguiente manera: Medical profession at a new millenium: statutes for medical practice regulations. Charter es más que regulación, es «estatuto», «constitución». De hecho, el término inglés procede de la expresión latina charta magna, utilizada el año 1215 en el documento de concesión de libertales del rey inglés Juan sin Tierra a los prelados y nobles. El texto latino se titula Magna Charta Libertatum, y la traducción inglesa dice: Great Charter. Se trata de un documento en que se fijan los derechos de los barones y terratenientes ingleses y se limita la autoridad absoluta del rey de Inglaterra. Se considera el documento básico de los derechos de los ciudadanos ingleses, así como el comienzo de las declaraciones de derechos humanos ${ }^{16}$. De ahí que el diccionario de Oxford defina charter como «una declaración escrita por un soberano o un gobernante concediendo ciertos derechos y privilegios a una población, compañía, universidad, etc.», y hace sinónima esa palabra de constitution o constitución.

Era necesario hacer este breve análisis del término charter para entender lo que se han propuesto las instituciones firmantes del documento citado, que son nada menos que el American Board of Internal Medicine, el American College of Physicians y la Federación Europea de Medicina Interna. La idea de estas tres corporaciones profesionales es que resulta necesario redefinir los derechos y libertades de la profesión médica. Esto se debe a que hay alguien o algo que está atentando contra esas libertades y que está ejerciendo o intentando ejercer un poder absoluto sobre los médicos, como en otro tiempo el rey Juan sin Tierra. ¿Quién es ése o qué es eso? He ahí la cuestión.

Para contestar a esta pregunta, abramos el texto. Su primer párrafo dice así: «En la actualidad los profesionales de la medicina experimentan una gran frustración a causa de los cambios en los sistemas de asistencia sanitaria que se están registrando en prácticamente todos los países industrializados, cambios que amenazan la naturaleza y los valores más intrínsecos de la profesión 
médica. Los encuentros celebrados entre la Federación Europea de Medicina Interna, el ACP-ASIM (American College of Physicians-American Society of Internal Medicine) y el ABIM (American Board of Internal Medicine) han confirmado que la concepción sobre la profesión que tienen los facultativos de sistemas sanitarios muy diversos guarda gran similitud. Compartimos la opinión de que el compromiso de la medicina con el paciente se enfrenta a toda una serie de desafíos impuestos por causas externas derivadas de los cambios que está experimentando la sociedad actual.»

Reparemos en lo que se nos dice. En primer lugar, que se están produciendo cambios profundísimos en los sistemas de asistencia sanitaria, sobre todo en los países industrializados. Segundo, que esos cambios amenazan la naturaleza y valores intrínsecos de la profesión médica. Tercero, que las concepciones de la profesión médica de las distintas organizaciones profesionales guardan gran similitud. Y cuarto, que estos desafíos están provocados por lo que llaman «causas externas». No se trata, pues, de que los médicos hayan cambiado su modo de entender la profesión, sino que estructuras o fuerzas ajenas a la profesión están intentando dar al traste con lo que los médicos consideran «valores intrínsecos» de su actividad, y en tanto que tales, irrenunciables.

Y de nuevo surge la pregunta: ¿cuáles son esos factores externos que amenazan a la profesión? Saltemos el cuerpo del artículo y vayamos a su párrafo final. Dice así: «La práctica de la medicina en la actualidad se enfrenta a desafíos sin precedentes en casi todas las culturas y sociedades. Estos desafíos se centran en las crecientes disparidades existentes entre las necesidades legítimas de los pacientes, los recursos disponibles para satisfacer dichas necesidades, la creciente dependencia de las fuerzas del mercado para transformar los sistemas sanitarios y la tentación de los médicos de abandonar su compromiso de velar por el bienestar de los pacientes. Con vistas a mantener la fidelidad del contrato de la medicina con la sociedad en estos tiempos difíciles, creemos que el cuerpo médico debe reafirmar su acatamiento activo de los principios de la profesión, en los que no sólo se engloba el compromiso personal de velar por el bienestar de los pacientes, sino también los esfuerzos colectivos por mejorar los sistemas de asistencia sanitaria en pro del bienestar de toda la sociedad. Los presentes Estatutos de la profesión médica tienen por objeto alentar dicho cumplimiento y presentar un programa de acción de alcance universal.»

Como se habrá podido advertir, se habla de la existencia de un «contrato» entre la profesión médica y la sociedad, que los autores ven de difícil cumplimiento. Los términos de ese contrato son los que intenta definir el artículo. Consta de tres principios:

1. Principio de primacía del bienestar del paciente

2. Principio de autonomía del paciente

3. Principio de justicia social.

Como puede advertirse, se trata de los tres principios de la bioética desde el Informe Belmont de 1978: Beneficencia, Autonomía y Justicia ${ }^{17}$.

Tras formular los tres citados principios, el texto añade las que llama diez responsabilidades de la profesión como un todo y de cada uno de los profesionales. Son los siguientes:

1. Compromiso con la competencia profesional

2. Compromiso de honestidad con los pacientes

3. Compromiso con la confidencialidad del paciente

4. Compromiso con el establecimiento de relaciones adecuadas con los pacientes 
5. Compromiso con una atención sanitaria de mayor calidad

6. Compromiso con la mejora del acceso a la asistencia sanitaria

7. Compromiso con la distribución de los recursos finitos

8. Compromiso con el saber científico

9. Compromiso con el mantenimiento de una confianza sólida gracias a la solución de los conflictos de interés

10. Compromiso con las responsabilidades profesionales.

No hay duda que los tres principios anteriores y estos diez compromisos permiten estipular un gran contrato de la profesión médica con la sociedad. Pero este contrato se halla amenazado por ciertos factores externos, en particular por los siguientes: «Las crecientes disparidades existentes entre las necesidades legítimas de los pacientes, los recursos disponibles para satisfacer dichas necesidades, la creciente dependencia de las fuerzas del mercado para transformar los sistemas sanitarios y la tentación de los médicos de abandonar la fidelidad del contrato de la medicina con la sociedad en estos tiempos difíciles.» Todos estos factores tienen importancia. Pero hay uno especialmente significativo, el primero. Veamos por qué.

\section{LAS FUERZAS DEL MERCADO Y EL SISTEMA SANITARIO}

La mayor amenaza que hoy se cierne sobre la medicina es «la creciente dependencia de las fuerzas del mercado para transformar los sistemas sanitarios». ¿A qué se están refiriendo? Desde aquí, desde Europa, no es fácil adivinarlo, sobre todo porque los redactores del texto han querido adrede aludir al problema sin hacerlo del todo explícito, sin duda por prudencia, o porque no se atreven.
Pero a cualquier lector norteamericano le resulta por demás transparente su sentido. Las instituciones sanitarias, por más que estuvieran en manos privadas, se habían venido considerando clásicamente como organizaciones non profit o sin ánimo de lucro. Esto ha cambiado drásticamente desde la época del presidente Reagan, es decir, a partir de 1981. Los hospitales han pasado a depender de compañías de seguros, fondos de inversión y empresas con ánimo de lucro, que intentan no sólo no perder dinero sino ganar cuanto más mejor en este campo de la sanidad. Esto significa que la sanidad ha empezado a considerarse un mercado y se rige por las leyes del mercado.

El tema no es nuevo. Se planteó ya en la época de Adam Smith, el padre de la teoría económica liberal. Como es bien sabido, ésta se basa en la crítica de la ineficiencia económica de los monopolios. Para Adam Smith, el monopolio corporativo de los médicos resultaba injustificable y cualquiera debería poder ejercer la medicina. En su opinión, cada paciente debía tener libertad de elegir su propio médico sobre la base de su reputación, no de su licencia, y cualquiera debería poder ejercer la medicina. Teóricos posteriores del laissez faire argumentaron que los escalafones acababan con los incentivos profesionales e impedían el desarrollo de la racionalidad en el consumidor.

Ante este ataque frontal, los médicos se defendieron afirmando la inaplicabilidad de los principios liberales al caso concreto de la sanidad. La medicina no podía ser considerada un mero comercio, ya que el médico se parecía más al padre o al sacerdote que al obrero o al comerciante. El cumplimiento de los fines específicos del médico, el servicio del enfermo y la autoridad profesional, exigían el disfrute de ciertos privilegios, como el monopolio, que vistos desde otra perspectiva son verdaderas cargas. Las leyes del libre mercado eran aptas para las actividades artesanales y mercantiles (es decir, para los 
oficios agrupados en las cofradías), ya que ellas sí se dedicaban al comercio de bienes y por tanto habían de regirse por las leyes del libre mercado, pero no para quienes lejos de vender bienes prestan servicios, como el Estado, la Iglesia, el Ejército o la Medicina. En una carta dirigida a Adam Smith, el eminente médico de Edimburgo William Cullen afirmaba que en medicina «ninguna de las razones aducidas para provocar la competencia tiene ninguna fuerza.[...] El pueblo está poco dotado para enjuiciar [...] los méritos del médico.[...] La vida y la salud de una gran porción de la Humanidad se halla en manos de gente ignorante.[...] Los legisladores deben tener especial cuidado de que este arte necesario llegue a la sociedad, en lo posible, salvo y útil ${ }^{18}$.

¿Qué significa esto? Permítaseme que lo exprese en los términos hoy usuales en los trabajos de sociología de las profesiones. Los profesionales están distinguiendo de modo drástico y radical entre lo que son «oficios», en los cuales sí es posible y deseable el libre mercado, y las «profesiones», en las cuales consideran necesario el monopolio. ¿Por qué? Porque gestionan cosas de tanto valor, que sólo pueden ejercerlas personas muy especiales. De hecho, lo que los médicos están diciendo es que las profesiones tienen lo que se suele denominar una «moralidad especial», distinta de la «moralidad común». Ya lo hemos visto antes. Como he expuesto en otros lugares, las profesiones clásicas, la de sacerdote, gobernante y médico, han venido caracterizadas a lo largo de los siglos por estas cinco notas: elección, segregación, privilegio, impunidad y autoridad ${ }^{19}$. La impunidad a que me refiero es la jurídica, y la autoridad es moral. Estas dos últimas notas han funcionado de modo excluyente, de modo que la impunidad jurídica debía ir unidad a la autoridad moral, y la falta de esta última, al sometimiento a las leyes. Éste es el planteamiento clásico, del que siguen echando mano los médicos desde la época de Adam Smith. Tal ha sido su vigencia a lo largo de la historia.
Ahora, dos siglos y poco después, el tema vuelve a surgir, pero con matices distintos. Ahora ya nadie reclama una moralidad especial para las profesiones. Esto se debe a que desde los años sesenta han sufrido un proceso rapidísimo de deterioro.

El prestigio social de las profesiones se ha deteriorado, y hoy casi nadie les concede una moralidad especial. Lo que suele defenderse hoy es que, como cualquier otra actividad humana, se halla sometida a la «moralidad común», si bien con lo que se denomina ahora «especificidad de rol». Pero es que además se ha producido otro cambio importantísimo, éste en la teoría económica. Ahora el debate en el sistema sanitario está en el binomio equidad-eficiencia. Los recursos son escasos. Esto es algo de lo que todos nos convencimos a partir de la crisis económica de 1973. ¿Cómo gestionarlos? Puede optarse por la equidad, como han hecho los sistemas europeos, creando sistemas públicos y universales de asistencia sanitaria, pero ello es a costa de la eficiencia. O puede optarse por la eficiencia, a costa de la equidad. Ha sido la opción del neoliberalismo que a partir de 1980 se impuso en la política norteamericana. La única manera de optimizar económicamente la sanidad es mediante el incremento de la eficiencia. Y esto se hace mejor en los sistemas privados y con ánimo de lucro que en los públicos y altruistas. En un sistema eficiente, la salud tendrá el coste que deba tener, y ése es el que tienen que pagar los ciudadanos, en este caso como en cualquier otro, siguiendo las relaciones de mercado. En las instituciones privadas, deben cerrarse todos aquellos servicios, por importantes que sean, que no pueden pagar los ciudadanos o para los que no hay demanda suficiente, ya que no resultan rentables. De ahí que tenga que haber instituciones públicas de beneficencia, que cubran esos servicios para quienes no pueden pagarlos y que también rescaten a los más pobres, pero sólo como procedimiento subsidiario del sistema privado y mercantil, que es el único capaz de dar eficiencia y calidad. 


\section{LIBRE MERCADO Y MANAGED CARE}

¿Cuál ha sido la expresión práctica de este nuevo enfoque? Es bien conocido de todos, el llamado managed care, término de nuevo difícil de traducir al español. En Puerto Rico se tradujo como «cuidado dirigido». En Argentina se ha usado «medicina gestionada» o «medicina de gestión». En España parece que se ha impuesto «gestión clínica», que desde luego es el término más eufónico. De todos es bien conocido este procedimiento. En él, el médico aparece no sólo como cuidador del paciente o agente del paciente, sino también como gestor de recursos. Es el problema de la «doble agencia», que tanto ha dado que hablar en estas dos últimas décadas. Sus perversiones son bien conocidas, ya que incentivan el ahorro a través de hacer partícipe al profesional de los beneficios, con lo que se le pone en la tentación continua de mirar por su peculio antes que por su paciente.

Por su parte, el American College of Physicians Center for Ethics and Professionalism, en colaboración con el Harvard Pilgrim Health Care Ethics Program, han constituido un Medicine as a Profession Managed Care Ethics Working Group, expresión que cabe traducir como «Grupo de trabajo sobre ética de la gestión clínica dentro del programa de medicina como profesión». Este grupo de trabajo ha publicado en julio de 2004 un excelente documento, titulado Ethics in Practice: Managed Care and the Changing Health Care Environment ${ }^{20}$. Este texto es ya mucho más concreto que el primero de los citados y analizados, y supone un avance significativo. Su tesis central es que todas las partes implicadas en la asistencia sanitaria, es decir, los proveedores (health plans), los compradores (purchasers, que son las empresas que contratan las pólizas con las compañías proveedoras), los clínicos y los pacientes deben participar en un diálogo público a fin de establecer las políticas institucionales y el modo como deben distribuirse los recursos. No pueden ser sólo los economistas, ni sólo los provee- dores de servicios quienes establezcan las políticas en materia de salud. Y ello porque la asistencia sanitaria es un bien social primario que no puede dejarse a las puras fuerzas del mercado. Es necesario tener en cuenta a los ciudadanos y a los profesionales. De no ser así, los médicos se verán en la desagradable circunstancia de no poder ejercer la profesión dignamente.

\section{LA EXIGENCIA DE PROFESIONALIDAD}

Si ahora volvemos al comienzo, al texto con que comenzó este movimiento, veremos que en él aparece un término que ha adquirido inusitada fuerza en estos últimos años: el de Medical Professionalism, profesionalismo médico. Tengo que decir que considero inadecuada esa traducción. Y ello porque en nuestro idioma casi todos los sustantivos acabados en «ismo» tienen un sentido claramente peyorativo. Profesionalismo designa entre nosotros el uso de la profesión para defender privilegios y prevendas; por tanto, el sacar provecho de los privilegios de la profesión: la defensa de unos profesionales por otros, la búsqueda de privilegios, etc. Este sentido negativo es el que ha adquirido en la polémica de los años sesenta y setenta en torno a la moralidad especial o común de la profesión médica. Profesionalismo ha sido y es el modo de designar el mal uso y los vicios de la profesión durante su etapa monopolista; por tanto, la defensa a ultranza del monopolio y los privilegios. De ahí que considere preferible no utilizar la expresión «profesionalismo médico», que sería la traducción más exacta de los términos ingleses. Durante algún tiempo he pensado que entre nosotros debía hablarse de un «nuevo profesionalismo», para distinguirlo claramente del clásico. Pero esto también tiene sus inconvenientes, ya que puede entenderse en el sentido de que de nuevo se quiere volver a la etapa del monopolio y los privilegios.

Lo que el término inglés professionalism significa es la realización correcta, a ser posi- 
ble excelente, de la actividad profesional. No sólo no tiene sentido negativo sino que lo tiene positivo. Por eso la mejor traducción a nuestro idioma de professionalism no es «profesionalismo» sino «profesionalidad». El Rey dijo de su esposa que era «una gran profesional». Eso es profesionalidad. Lo cual no significa actuar como en épocas pasadas. Ya no se trata de ejercer la profesión de modo monopolista. Muy al contrario: de lo que se trata es de colaborar con los gestores y con los ciudadanos en la definición de los objetivos de la sanidad. Hemos pasado del monopolismo médico al monopolio de la economía. Eso no es de recibo. Es preciso llegar a un equilibrio o acuerdo que permita cohonestar las exigencias de la economía con el ejercicio digno de la profesión y la búsqueda del beneficio de los pacientes. ¿Será esto posible? Esperemos que sí.

Ética profesional y ética institucional: ¿convergencia o conflicto? Es indudable que se trata de dos instancias distintas, con objetivos e intereses diversos, y por tanto conflictivos entre sí. Pero con una finalidad común: la salud y el bienestar de los pacientes. De ahí la necesidad de la convergencia. Cómo conseguir ésta parece que va a ser el gran tema durante los próximos años.

\section{BIBLIOGRAFÍA}

1. Parsons T. The professions and social structure (1939). In: T. Parsons ed. Essays in sociological theory. New York: Free Press; 1947, p. 56-77.

2. Freidson E. Profession of Medicine. New York: Dodd, Mead; 1970.

3. Veatch RM. Professional Medical Ethics: The Grounding of Its Principles. J Med Philos 1979;4(1):1-18

4. Aristóteles, Pol I 1: 1252 a 1-2.

5. Aristóteles, Et Nic I 1: 1094 a 1-3.

6. Platón. Lisis 219 a.

7. Kass L. Regarding the end of medicine and the pursuit of health. The Public Interest 1975;40:11-42.
8. Pellegrino ED. Philosophy of Medicine: Problematic and Potential. J Med Philos 1976;1(1):5-31.

9. MacIntyre A. After Virtue. London: Duckworth; 1981.p. 175.

10. Fuller LL. The Morality of Law, Revised Edition. New Haven: Yale University Press; 1969.

11. Finnis J. Natural Law and Natural Rights. Oxford: Clarendon Press; 1980

12. Ladd J. The internal morality of medicine: An essential dimension of the physician-patient relationship. In: E. Shelp (Ed.) The Clinical Encounter: The moral fabric of the physician-patient relationship. Dordrecht: D. Riedel; pp. 209-231.

13. Wynia MK, Latham SR, Kao AC, Berg JW, Emanuel LL. Medical professionalism in society. $\mathrm{N}$ Engl J Med 1999 Nov 18;341(21):1612-6.

14. Project of the ABIM Foundation, ACP-ASIM Foundation, and European Federation of Internal Medicine. Medical professionalism in the new millennium: a physicians' charter. Lancet 2002;359(9305):520-2, y Ann Intern Med 2002; 136(3):243-6.

15. Un proyecto de la Fundación ABIM, la Fundación ACP-ASIm y la Federación Europea de Medicina Interna, La profesión médica en el nuevo milenio: estatutos para la regulación de la práctica médica. Med Clin (Barc) 2002;118(18):704-6.

16. Peces-Barba Martínez G, Fernández Liesa CR, Llamas Gascón A, Barranco Avilés MC, Domínguez Redondo E, Escudero Alday R, Pavón Pérez JA, y Rodríguez Uribes JM. Textos básicos de derechos humanos. Pamplona: Aranzadi; 2001.

17. The National Commission for the Protection of Human Subjects of Biomecial and Behavioral Research, The Belmont Report: Ethical Principles and Guidelines for the Protection of Human Subjects of Research. Disponible en: http://ohsr.od.nih. gov/guidelines/belmont.html.

18. Cowen DL. Liberty, Laissez-Faire and Licensure in Nineteenth Century Britain. Bull Hist Med 1969;43: 31 .

19. Gracia D. Como arqueros al blanco, Madrid: Triacastela; 2004.p. 247-50.

20. Medicine as a Profession Managed Care Ethics Working Group Statement. Ethics in Practice: Managed Care and the Changing Health Care Environment. Ann Intern Med 202004 ; 141(2):131-36. 